\title{
High-mobility group box-1 protein, lipopolysaccharide-binding protein, interleukin-6 and C-reactive protein in children with community acquired infections and bacteraemia: a prospective study
}

\author{
Jana Pavare ${ }^{1 *}$, Ilze Grope ${ }^{1}$, Imants Kalnins², Dace Gardovska ${ }^{1}$
}

\begin{abstract}
Introduction: Even though sepsis is one of the common causes of children morbidity and mortality, specific inflammatory markers for identifying sepsis are less studied in children. The main aim of this study was to compare the levels of high-mobility group box-1 protein (HMGB1), Lipopolysaccharide-binding protein (LBP), Interleukin-6 (IL-6) and C-reactive protein (CRP) between infected children without systemic inflammatory response syndrome (SIRS) and children with severe and less severe sepsis. The second aim was to examine HMGB1, LBP, IL6 and CRP as markers for of bacteraemia.
\end{abstract}

Methods: Totally, 140 children with suspected or proven infections admitted to the Children's Clinical University Hospital of Latvia during 2008 and 2009 were included. Clinical and demographical information as well as infection focus were assessed in all patients. HMGB1, LBP, IL-6 and CRP blood samples were determined. Children with suspected or diagnosed infections were categorized into three groups of severity of infection: (i) infected without SIRS ( $n=36)$, (ii) sepsis $(n=91)$ and, (iii) severe sepsis $(n=13)$. They were furthermore classified according bacteraemia into (i) bacteremia $(n=30)$ and (ii) no bacteraemia $(n=74)$.

Results: There was no statistically significant difference in HMGB1 levels between children with different levels of sepsis or with and without bacteraemia. The levels of LBP, IL-6 and CRP were statistically significantly higher among patients with sepsis compared to those infected but without SIRS $(p<0.001)$. Furthermore, LBP, IL-6 and CRP were significantly higher in children with severe sepsis compared to those ones with less severe sepsis $(p<$ 0.001). Median values of LBP, IL6 and CRP were significantly higher in children with bacteraemia compared to those without bacteraemia. The area under the receiver operating curve (ROC) for detecting bacteraemia was 0.87 for both IL6 and CRP and 0.82 for LBP, respectively.

Conclusion: Elevated levels of LBP, IL-6 and CRP were associated with a more severe level of infection in children. Whereas LBP, IL-6 and CRP seem to be good markers to detect patients with bacteraemia, HMGB1 seem to be of minor importance. LBP, IL-6 and CRP levels may serve as good biomarkers for identifying children with severe sepsis and bacteraemia and, thus, may be routinely used in clinical practice.

\footnotetext{
* Correspondence: jana.pavare@inbox.lv

${ }^{1}$ Riga Stradins University, Chair of Pediatrics, Riga, Latvia
} 


\section{Background}

Sepsis in children population is one of the common causes of morbidity and mortality in the word, with > 42000 cases of severe sepsis in United States annually and millions worldwide [1,2]. Hospital mortality among USA children with severe sepsis was $10.3 \%$ [3]. In Latvia between 1995 and 2000, 82 children with sepsis were treated in the only tertiary level hospital in country, with $24.4 \%$ of these cases being fatal [4]. Early recognition and prompt initiation of therapy are the most important measures in reducing mortality from sepsis [5-7]. The timely diagnosis of sepsis in children remains difficult due to a variety of reasons: early warning signs and symptoms often are non-specific, the identification process of microorganisms in culture is prolonged.

As a milestone in clinical recognition of sepsis in children became The International Pediatric Sepsis Consensus Conference in 2002 where specific clinical definitions of systemic inflammatory response syndrome (SIRS) and sepsis in children were define [5].

The diagnosis of bacteraemia is still difficult due to prolonged time for microbiological analysis (48-72 hours) and due to the problem that not all bacteria are detectable. However, recent studies have revealed that some inflammatory markers such as the high-mobility group box-1 protein (HMGB1) [8-12], the lipopolysaccharide-binding protein (LBP) [13-16] and the Interleukin-6 (IL-6) [17-20] may be detectable already in the early state of infection and bacteraemia. Whereas the findings in regard HMGB1 were inconsistent in identification of patients with infections and those without [9-12], IL-6 has been suggested to be a suitable early inflammatory marker, with levels correlating well with the severity and prognosis of sepsis $[19,20]$. Increased serum LBP levels have been reported in neonatal early onset sepsis [14], and is reported to be a better marker in critically ill neonates and children than other markers, such as C-reactive protein, procalcitonin and interleukin-6 (IL-6) $[15,16]$.

Comparatively fewer studies on inflammatory markers in infected children as well in children with bacteraemia have been made, lacking in numbers for LBP, HMGB1. Taking into account the new definition of sepsis in children [21] - systemic inflammatory response syndrome (SIRS) with apparent or confirmed infection - there is a clear need for accurate and rapid laboratory indicators for the early diagnosis of bacteraemia and sepsis in children. The main aim of this study was to compare the levels of HMGB1, LBP, IL- 6 and CRP between infected children without systemic inflammatory response syndrome (SIRS) and children with sepsis of different severity levels. Furthermore, a secondary aim was to examine the ability of HMGB1, LBP, IL6 and CRP as markers for early detection of bacteraemia.

\section{Methods \\ Material}

All patients admitted to the Children's Clinical University Hospital between January 2008 and May 2009 whose parents agreed to participate were included in this study. The hospital is the only tertiary level children hospital of Latvia that serves a population of $\sim 420,000$ children. The inclusion criteria for the study were the suspected diagnosis of an infection by the referring physician and age from 1 week to 18 years. Exclusion criteria were antibacterial therapy within the last $48 \mathrm{~h}$, immunodeficiency, chronic liver or kidney illness, vaccination within 5 days before the start of the illness, any chronic illness that alters CRP levels, congenital metabolic defects, chromosomal anomalies, and use of corticosteroids or immunosuppressant medications.

A total of 140 patients fulfilled the entry criteria (infection) and were enrolled. The percentage of infected patients with sepsis based on SIRS criteria was 74\% ( $\mathrm{n}=$ 104) Patients were classified at the time of inclusion into three following groups of severity of infection: (i) infected without SIRS $(\mathrm{n}=36)$, (ii) sepsis $(\mathrm{n}=91)$ and, (iii) severe sepsis $(n=13)$. They were furthermore classified according to bacteraemia into (i) patients with bacteremia and/or high possibility of bacteraemia ( $\mathrm{n}=$ $30)$ and (ii) patients without bacteraemia $(\mathrm{n}=74)$.

\section{Definition of infection}

SIRS criteria were assessed, taking into account the values of vital signs appropriate to the child's age group, including body temperature, heart rate, respiratory rate and leukocyte count [21]. Classification of the status of SIRS was done by two clinicians without knowing the laboratory results. Sepsis was defined as systemic inflammatory response syndrome (SIRS) in the presence of suspected or proven infection. The diagnose of infection was verified thereafter by positive bacterial culture, tissue strain. Furthermore, evidence of infection included positive clinical findings, imaging or laboratory tests (white blood cells in sterile body fluid, pneumonia in radiographic imaging, petechial or purpuric rash) [21]. For sepsis severity definition the International Pediatric Sepsis Consensus Conference classification was used. Sepsis was defined as severe when the patient had one of the following: cardiovascular dysfunction (hypotension $<5^{\text {th }}$ percentile for age, or systolic blood pressure $<2$ SD below normal of age despite $>40 \mathrm{ml} / \mathrm{kg}$ of isotonic intravenous fluid in 1 hour) or need for vasoactive drug to maintained blood pressure or 2 of the following: unexplained metabolic acidosis, base deficit $>5.0 \mathrm{mEq} / \mathrm{L}$, increased arterial lactate $>2$ times upper limit of normal, oliguria (urine output $<0.5 \mathrm{ml} / \mathrm{kg} / \mathrm{h}$ ), prolonged capillary refill $>5 \mathrm{sec}$, core to periphere temperature 
gap $>3^{\circ} \mathrm{C}$ or acute respiratory distress syndrome (ARDS) as defined by the presence of a $\mathrm{PaO} 2 / \mathrm{FiO} 2$ ratio $<300$ $\mathrm{mm} \mathrm{Hg}$, bilateral infiltrates on chest radiograph, and no evidence of left heart failure or sepsis plus 2 or more organ dysfunctions (respiratory, renal, neurological, hematological or hepatic). Septic shock was defined as sepsis and cardiovascular organ dysfunction. Multiple Organ Dysfunction Syndrome was defined as presence of altered organ function such that homeostasis cannot be maintained without medical intervention [21].

Possible bacteraemia was defined based on the consensus definitions for bloodstream infections in children [22]. The definition includes the presence of SIRS and convincing focus of bacterial infection (pulmonary infiltrates, soft tissue infections, pyelonephritis, osteomyelitis) given a negative blood culture.

\section{Measurements}

A venous blood sample was drawn from each patient under local anesthesia induced by an EMLA patch. All analyzes were made immediately, excepted HMGB, where the samples were processed at frozen at $-80^{\circ} \mathrm{C}$ within 30 min of sampling.

Clinical and demographic data of the patients were assessed and biochemical markers of inflammation (HMGB1, LBP, IL-6, CRP) were determined.

\section{Laboratory assays}

HMGB1 levels were measured with a commercially available enzyme-linked immunosorbent assay (HMGB1 ELISA kit; Shino-Test Corporation, Tokyo, Japan). The measuring range was 1 to $80 \mathrm{ng} / \mathrm{ml}$, the coefficient of variation being $<10 \%$. Recovery of HMGB1 in this ELISA was $80-120 \%$.

IL6 and LBP were determined with a chemiluminescent immunometric assay Immulite 2000 (Siemens Medical, Germany). The analytical sensitivity for IL6 was $2 \mathrm{pg} / \mathrm{ml}$ and $0.2 \mu \mathrm{g} / \mathrm{ml}$ for LBP.

CRP levels were measured by the latex method (COBAS INTEGRA; Roche professional Diagnostics), the lowest assay sensitivity being $0.085 \mathrm{mg} / \mathrm{L}$. CRP levels $<20 \mathrm{mg} / \mathrm{L}$ were accepted as normal.

All the laboratory analyses were carried out at the Children Clinical University Hospital (Latvia), except for HMGB 1 which was analyzed in the laboratory of Clinical Immunology and Immunogenetic, Riga Stradins University.

\section{Ethical considerations}

The study protocol was approved by the Central Medical Ethics Committee of Latvia. Each child's parents signed a written consent form. All patients had received the standard of care according to hospital guidelines.

\section{Statistical analyses}

The data was analyzed using SPSS version 17.0 for Windows and Epi Info 2000. The results are presented as numbers $(\mathrm{n})$, frequencies (\%), means with respective standard deviation (SD) and as medians with their interquartile ranges (IQR). Differences in continuous variables between different groups of infections were performed using the Kruskal - Wallis test and Mann Whitney tests as the continuous variables did not follow a normal distribution. Correlation analysis was carried out calculating the Spearman rank coefficient and the respective $\mathrm{p}$-value.

To assess the performance of the selected biomarkers with respect to bacteraemia, receiver operating characteristics (ROC) curves, sensitivity and specificity values were calculated. The $95 \%$ confidence interval and $\mathrm{p}$ value were reported for the area under the curve (AUC) for the optimal cut-off levels. A p-value of less than 0.05 (two-tailed) was considered statistically significant for all tests.

\section{Results}

\section{Baseline characteristics of the study sample}

The baseline characteristics of the study sample are presented in Table 1. The mean age of was 84.6 months for the infected patients without SIRS, 70.4 months for sepsis patients, and 97.5 months for the severe sepsis patients, respectively.

The number of infections according to age-groups and infection focus can be found in table 2. The most common infections were upper and lower respiratory track infections as well as gastroenteritis. Bacteraemia was confirmed by 2 separate positive blood cultures. Grampositive bacteria were identified in 5 patients; Gramnegative bacteria in 3 patients, patients with strongly suspected bacteraemia without microbiological confirmation had pneumonia (11 children), skin/soft tissue infections ( 6 children), pyelonephritis (4 children), osteomyelitis (1 child).

\section{Differences in levels of HMGB1, LBP, IL6 and CRP between groups of different severity of infection}

HMGB1 levels in infected patients without SIRS did not statistically significantly differ from those with sepsis or sever sepsis. In addition there was no statistically significant difference observed in HMGB1 levels between children with sepsis and those with severe sepsis (Table 3). LBP, IL-6 and CRP levels were significantly higher among sepsis patients compared with infected children without SIRS $(\mathrm{p}<0.001)$ and were significantly higher in the severe sepsis group compared with the less severe sepsis group $(\mathrm{p}<0.001$ for all differences). 
Table 1 Baseline characteristics of the study sample according to severity of infection.

\begin{tabular}{lccc}
\hline & $\begin{array}{c}\text { Infected patients without SIRS } \\
(\mathbf{n}=\mathbf{3 6})\end{array}$ & $\begin{array}{c}\text { Sepsis patients } \\
(\mathbf{n}=\mathbf{9 1})\end{array}$ & $\begin{array}{c}\text { Severe sepsis patients } \\
(\mathbf{n}=\mathbf{1 3})\end{array}$ \\
\hline Boys (n) & 20 & 49 & 11 \\
Girls (n) & 16 & 42 & 2 \\
Age (months) & $84.6 \pm 77.0^{1}$ & $70.4 \pm 69.7$ & $97.5 \pm 88.2$ \\
& & & $2.9 \pm 1.8$ \\
Number of days of symptoms at hospital admission & $3.8 \pm 2.4$ & $3.3 \pm 2.5$ & $3.8 \pm 2.0$ \\
Number of day of symptoms at study entry & $5.5 \pm 3.2$ & $4.5 \pm 3.0$ & $15.4 \pm 13.5$ \\
Treatment time in the hospital (days) & $6.3 \pm 4.2$ & $8.6 \pm 5.9$ & \\
\hline
\end{tabular}

${ }^{1}$ mean \pm standard deviation.

Table 2 Age groups and characteristics of infections among children according to severity of sepsis.

\begin{tabular}{|c|c|c|c|}
\hline & $\begin{array}{l}\text { Infected patients } \\
\text { without SIRS } \\
(\mathrm{n}=36)\end{array}$ & $\begin{array}{c}\text { Sepsis } \\
\text { patients } \\
(\mathrm{n}=91)\end{array}$ & $\begin{array}{c}\text { Severe sepsis } \\
\text { patients } \\
(\mathrm{n}=13)\end{array}$ \\
\hline \multicolumn{4}{|l|}{ Age group } \\
\hline 0 days - 1 week & 0 & 0 & 0 \\
\hline $\begin{array}{l}1 \text { week to } 1 \\
\text { month }\end{array}$ & 1 & 4 & 1 \\
\hline $\begin{array}{l}1 \text { month to } 1 \\
\text { year }\end{array}$ & 7 & 23 & 2 \\
\hline 2 to 5 years & 11 & 30 & 4 \\
\hline 6 to 12 years & 6 & 15 & 0 \\
\hline 13 to $<18$ years & 11 & 19 & 6 \\
\hline \multicolumn{4}{|l|}{ Infection focus } \\
\hline $\begin{array}{l}\text { Upper respiratory } \\
\text { tract }\end{array}$ & 13 & 39 & - \\
\hline $\begin{array}{l}\text { Lower respiratory } \\
\text { tract }\end{array}$ & 8 & 27 & 7 \\
\hline Gastroenteritis & 11 & 13 & - \\
\hline Pyelonephritis & - & 4 & - \\
\hline $\begin{array}{l}\text { Skin/Soft tissue } \\
\text { infection }\end{array}$ & - & 4 & 3 \\
\hline Osteomyelitis & - & 2 & 1 \\
\hline Meningitis & - & - & 2 \\
\hline $\begin{array}{l}\text { Occult } \\
\text { bacteremia }\end{array}$ & - & 2 & - \\
\hline Cistitis & 4 & - & - \\
\hline Total & 36 & 91 & 13 \\
\hline
\end{tabular}

${ }^{1}$ systemic inflammatory response syndrome.

\section{Differences in levels of HMGB1, LBP, IL6 and CRP} between children with and without bacteraemia

There was no statistically significant difference in HMGB1 levels between children patients with and without bacteremia (Table 4). However, LBP, IL-6 and CRP levels were statistically significantly higher in bacteremic patients compared to those without bacteraemia ( $<<0.001)$.

\section{Correlations between HMGB1, LBP, IL-6 and CRP in children}

No correlations were found between HMGB1 and any of the other three biomarkers (Table 5). LBP correlated well with IL-6 $(r=0.688, \mathrm{p}<0.001)$ and CRP $(r=$
$0.741, \mathrm{p}<0.001)$. In addition, a strong correlation was found between IL-6 and CRP $(r=0.632, p<0.001)$.

\section{Diagnostic abilities of HMGB1, LBP, IL6 and CRP in} detecting children with bacteremia

In receiver operating curve (ROC) analysis for detecting bacteraemic patients, both IL6 and CRP had areas under the curve (AUC) of 0.87 (Figure 1). The 95\% confidence interval (CI) was 0.78 - 0.96 for IL6 and 0.79 0.95 for CRP, respectively. LBP had an AUC of 0.82 (95\% CI 0.73 - 0.91). The sensitivity using a cut-off level of $26.6 \mu \mathrm{g} / \mathrm{ml}$ (LBP), $58.7 \mathrm{pg} / \mathrm{ml}$ (IL6) and $97 \mathrm{mg} / \mathrm{l}$ (CRP) were $80 \%$ in all three markers (Table 6). The corresponding false-positive rates were 55\% (LBP), $81 \%$ (IL6) and $77 \%$ (CRP) for detecting children with bacteraemia.

\section{Discussion}

Our study showed that the detectable levels LBP, IL-6 and CRP differ in the earl stage of infection dependent on severity of infection. Furthermore, the detectable levels of these biomarkers differ in children with bacteraemia and those without. In addition, our results showed that LBP, IL-6 and CRP can be used as biomarkers in early detection of bacteraemia.

To date only a few studies are available on the association between SIRS and sepsis in children as the definitions of SIRS and sepsis in children have only recently been adopted.

The inflammatory biomarkers - CRP, IL-6 in children population have been studied comparatively widely, clinical studies of LBP in children are limited and to our knowledge HMGB1 have not been studied in infected children population [14-18]. The previous studies in children population are performed in very restricted patients' populations - mainly neonatal age, which have very age specific physiological conditions with possible influence on results; severe ill patients from intensive care units. Our study, however, included children from all-age groups covering a large spectrum of children with different grades of infections. 
Table 3 Levels of HMGB1, LBP, IL-6 and CRP in infected children without SIRS, with sepsis and with severe sepsis.

\begin{tabular}{|c|c|c|c|c|}
\hline Biomarker & $\begin{array}{l}\text { Infected patients without SIRS } \\
(\mathrm{n}=36)\end{array}$ & $\begin{array}{l}\text { Sepsis patients } \\
(\mathrm{n}=91)\end{array}$ & $\begin{array}{c}\text { Severe sepsis patients } \\
(\mathrm{n}=13)\end{array}$ & p-value ${ }^{a}$ \\
\hline \multicolumn{5}{|c|}{ HMGB1 (ng/ml) } \\
\hline Median & 2.5 & 3.0 & 3.1 & NS \\
\hline IQR & $0.3-5.9$ & $1.0-7.3$ & $1.3-14.3$ & \\
\hline$p$-value ${ }^{b}$ & & NS & NS & \\
\hline \multicolumn{5}{|c|}{ Lipopolysaccharide-binding protein ( $\mu \mathrm{g} / \mathrm{ml})$} \\
\hline Median & 14.7 & 26.4 & 79.7 & $<0.001$ \\
\hline IQR & $8.7-26.0$ & $17.5-42.2$ & $57.8-90.6$ & \\
\hline p-value & & $<0.001$ & $<0.001$ & \\
\hline \multicolumn{5}{|c|}{ Interleukin 6 (pg/ml) } \\
\hline Median & 8.9 & 32.1 & 290.0 & $<0.001$ \\
\hline IQR & $4.0-18.8$ & $13.8-68.1$ & $67.9-522.6$ & \\
\hline$p$-value & & $<0.001$ & $<0.001$ & \\
\hline \multicolumn{5}{|c|}{ C-reactive protein (mg/l) } \\
\hline Median & 12.0 & 63.0 & 211.8 & $<0.001$ \\
\hline IQR & $3.1-36.6$ & $27.0-114.5$ & $108.0-318.6$ & \\
\hline$p$-value ${ }^{b}$ & & $<0.001$ & $<0.001$ & \\
\hline
\end{tabular}

Data presented as median and interquartile range (IQR). SIRS, systemic inflammatory response syndrome. HMGB1, high mobility box-1 protein; LBP, lipopolysaccharide-binding proteine; IL-6, interleukine-6; CRP, C-reactive protein. NS, not significant. ${ }^{\mathrm{a} K r u s k a l-W a l l i s}$ tests. ${ }^{\mathrm{b}}$ Mann Whitney two independent sample tests, compared with the previous group in the table.

Table 4 Levels of HMGB1, LBP, IL-6 and CRP in children with and without bacteraemia.

\begin{tabular}{|c|c|c|c|}
\hline Biomarker & Infection without bacteraemia $(n=74)$ & $\begin{array}{l}\text { Infection with bacteraemia } \\
\qquad(\mathrm{n}=30)\end{array}$ & p-value ${ }^{1}$ \\
\hline $\mathrm{HMGB1}^{2}(\mathrm{ng} / \mathrm{ml})$ & $3.0(1-7.4)^{6}$ & $3.2(1.2-10.9)$ & $\mathrm{ns}^{7}$ \\
\hline $\operatorname{LBP}^{3}(\mu \mathrm{g} / \mathrm{ml})$ & $23.7(16.6-38.5)$ & $63.4(28.3-86)$ & $<0.001$ \\
\hline$\| \mathrm{L}-6^{4}(\mathrm{pg} / \mathrm{ml})$ & $21.2(10.5-46.6)$ & $178.1(62.3-464.8)$ & $<0.001$ \\
\hline $\mathrm{CRP}^{5}(\mathrm{mg} / \mathrm{l})$ & $54.5(16.1-91.1)$ & $212.8(100.7-247.4)$ & $<0.001$ \\
\hline
\end{tabular}

${ }^{1}$ Mann - Whitney test.; ${ }^{2}$ high mobility box-1 protein; ${ }^{3}$ lipopolysaccharide-binding proteine; ${ }^{4}$ interleukine- 6 ; ${ }^{5} \mathrm{C}$-reactive protein; ${ }^{6}$ median and interquartile range (IQR). ${ }^{7}$ not significant.

Table 5 Correlations between HMGB1, LBP, IL-6 and CRP in children with infections

\begin{tabular}{|c|c|c|c|c|c|c|c|c|}
\hline HMGB1 versus marker & Spearman's & $P$ value & LBP versus marker & Spearman'sr & $P$ value & IL6 versus marker & Spearman's $r$ & $P$ value \\
\hline LBP & 0.013 & $0,899^{1}$ & HMGB1 & 0.013 & 0,899 & HMGB1 & 0.115 & 0,243 \\
\hline IL6 & 0.115 & $0,243^{1}$ & IL6 & 0.688 & $<0.001$ & LBP & 0.688 & $<0.001$ \\
\hline CRP & 0.045 & $0,652^{1}$ & CRP & 0.741 & $<0.001$ & CRP & 0.632 & $<0.001$ \\
\hline
\end{tabular}

${ }^{1}$ not significant.

The second aim of our study was to facilitate the diagnosis of bacteraemia, as the recognition process of pathogen in the blood is still not perfect. Frequently bacteraemis is strongly suspected without microbiological confirmation and physician institutes the treatment as for bacteraemeic patient. To improve the diagnosis of possible bacteraemia by inflammatory markers, and speed the sequential start of appropriate treatment, we include patients with the high suspicions of bacterial infection (probable bacteraemia) in the group of bacteraemic patients. It is possible that besides gold standard positive blood culture, the inflammatory biomarkers could speed the diagnosis of bacteraemia. The consequential of it, is the heterogeneity of the bacteraemic patients group, which could be evaluate as the drawback.

HMGB1 has been known from many years as chromosomal protein, but in recent years it has been very intensively investigated as a proinflammatory cytokine [9,23]. In 1999, Wang et al [24] found increased levels of HMGB1 in 25 critically ill patients with sepsis, and significantly higher levels in those that succumbed to the disease. Similar findings were reported by Hatada et al. [11] who detected moderately elevated HMGB1 levels in patients with infectious diseases and highest HMGB1 levels in patients who died. Gaini et al. [10] maintained that HMGB1 levels failed to discriminate between internal medicine department patients with infection and 


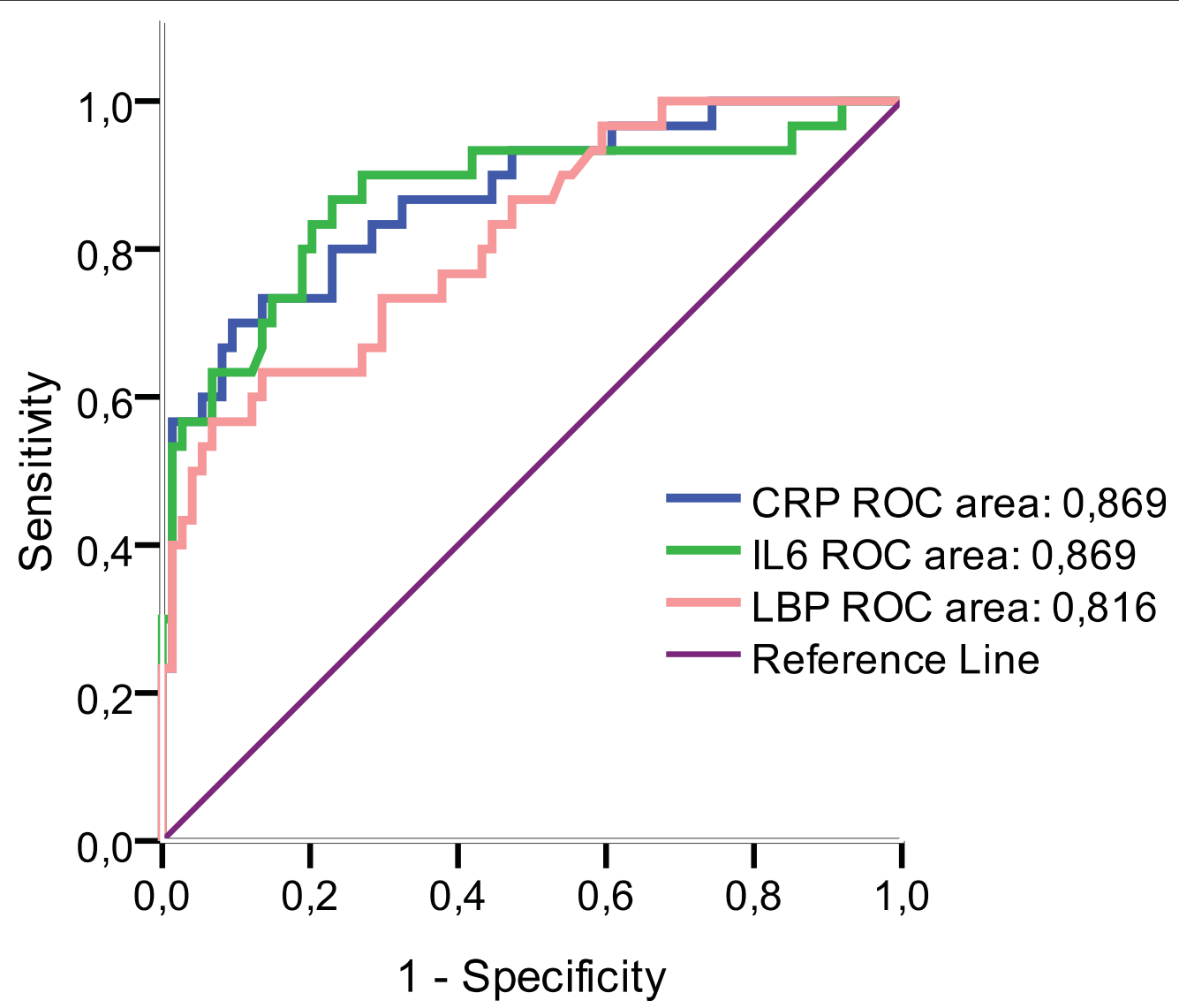

Figure 1 Receiver operating curves (ROC) of LBP, IL-6 and CRP in detecting bacteraemia in children. LBP, lipopolysaccharide-binding proteine; IL-6, interleukin-6; CRP, C-reactive protein $(p<0.001)$.

Table 6 Sensitivity and specificity of LBP, IL-6 and CRP according to the optimal cut-off levels in detecting children with bacteraemia.

\begin{tabular}{lccc}
\hline Marker & Cut-off level & Sensitivity (\%) & Specificity (\%) \\
\hline $\mathrm{LBP}^{1}$ & $26.6 \mu \mathrm{g} / \mathrm{ml}$ & 80 & 55 \\
$\mathrm{IL}-6^{2}$ & $58.7 \mathrm{pg} / \mathrm{ml}$ & 80 & 81 \\
$\mathrm{CRP}$ & $97 \mathrm{mg} / \mathrm{l}$ & 80 & 77 \\
\hline
\end{tabular}

${ }^{1}$ lipopolysaccharide-binding protein; ${ }^{2}$ interleukin-6; ${ }^{3} \mathrm{C}$-reactive protein

those without infection, but HMGB1 levels were significantly higher in patients compared with healthy controls. Similar findings were reported by Sunden-Cullberg et al. [25], who noted high HMGB1 levels in patients with sepsis and septic shock, but found no correlation between HMGB1 concentration and the severity of illness. Angus et al. [26] found that HMGB1 levels did not differ between those with and without sepsis. One possible explanation for these divergent results could be the different laboratory methods used (Western blot and ELISA). Several authors $[8,27]$ have stated that in studies where blotting methods were used, higher levels of HMGB1 in range from $84 \mathrm{ng} / \mathrm{ml}$ to over $340 \mathrm{ng} / \mathrm{ml}$ were observed $[9,25,26]$. Using HMGB1 ELISA techniques, markedly lower HMGB1 levels were found. Hatada et al. [11] observed median HMGB1 levels of 4.5 $\mathrm{ng} / \mathrm{ml}]$ in infected patients. HMGB1 levels of $7.7 \mathrm{ng} / \mathrm{ml}$ were measured by Yasuda et al. [28] in infected patients with severe pancreatitis. Gaini et al, [10] in infected patients without sepsis in one of their studies noted median HMGB1 levels of $2.41 \mathrm{ng} / \mathrm{ml}$, and median levels of $3.4 \mathrm{ng} / \mathrm{ml}$ in another study [12] which is comparatively close to our HMGB1 result in this patients' group - $2.5 \mathrm{ng} / \mathrm{ml}$. Mean levels of HMGB1 in sepsis patients in our study was $3.0 \mathrm{ng} / \mathrm{ml}$, which are in line with the HMGB1 levels in sepsis patients found in the studies by Gaini et al $[10,12]$. Furthermore, we did not found a significant difference between HMGB1 levels in infected patients without SIRS and patients with sepsis. These findings are in line with those from Gaini et al [12] as well. In our study using an ELISA technique, median HMGB1 levels were $2.5-3.2 \mathrm{ng} / \mathrm{ml}$ which correlate with the lower HMGB1 levels observed in others studies where ELISA technique was used. In contrast to another study [12], we did not found a significant difference between HMBG1 levels in bacteraemic and non bacteraemic patients. This may be due to the fact that in our 
study not only bacteraemic patients, but also patients with possible bacteraemia were considered as having bacteraemia introducing a misclassification bias. Another possible explanation may be the different age of the children in our study compared to the one conducted by Gaini et al. The HMGB1 is a "late onset" proinflammatory cytokine, but our population was sampled at the early stage of disease. This may be a reason for not finding a significant difference in HMBG1 levels in our study groups.

LBP is a comparatively recently identified protein synthesized mainly in liver. It binds to lipopolysaccharide of Gram negative bacteria, and elevated levels have been seen in infections caused by Gram positive bacteria both in adult $[29,30]$ and children populations [15]. We found a moderate correlation between LBP and CRP, which concurs with the findings of Gaini et al. [12] and partly with their findings in their other publication where a strong correlation was found [31]. We saw a moderate correlation between LBP and IL6, which was also found by Gaini and collegues[31]. In their other study [12], these authors noted a weak correlation between LBP and IL6. In our study LBP levels in sepsis patients (median $26.4 \mu \mathrm{g} / \mathrm{ml}$ ) correlates very closely with data from Pavcnik-Arnol [16] where LBP concentrations in SIRS patients with sepsis from population of critically ill neonates were $27.1 \mu \mathrm{g} / \mathrm{ml}$. Gaini et al. in their studies in sepsis patients accordingly observed LBP levels of $33.5 \mu \mathrm{g} / \mathrm{ml}$ and $63.3 \mu \mathrm{g} / \mathrm{ml}[10,12]$. In our study patients with severe sepsis median LBP level was $79.7 \mu \mathrm{g} / \mathrm{ml}$ which correlate with Gaini et al. [12] results - LBP levels in severe sepsis patients were $88.7 \mu \mathrm{g} / \mathrm{ml}$. The levels of LBP were significantly different among infected patients with SIRS and sepsis patients, as well among severe sepsis and sepsis patients which correspondent to the findings from Gaini et al. studies [10,12,31]. In our study LBP levels were significantly different among patients with bacteraemia and without bacteraemia, these results are in line with findings by Gaini et al. [12]. In our study LBP with an AUC of 0.82 performed well on ROC analysis to examine diagnostic abilities in detecting bacteraemia, which correlates with the study by PavcnikArnol et al. [32] where AUC values for LBP in diagnosis of bacterial sepsis were 0.82 in older children, 0.93 in neonates over $48 \mathrm{~h}$ and 0.97 in neonates aged under 48 h. LBP in Gaini at al. [12] study in adult patients population with AUC of 0.74 did not perform well in ROC analysis examining its ability to identify bacteraemic patients. In our study using a cut-off level of $26.6 \mu \mathrm{g} / \mathrm{ml}$, LBP had a sensitivity of $80 \%$ and a specificity of $55.4 \%$ in diagnosis of bacteraemia which rather correlates with a cut-off level for LBP of $20 \mu \mathrm{g} / \mathrm{ml}$ with $91 \%$ sensitivity and $85 \%$ specificity by Pavcnik-Arnol [16] in neonates $<48 \mathrm{~h}$ of age and cutoff $13.3 \mathrm{mg} / \mathrm{l}$ for children age.
The levels of the inflammatory cytokine IL6 in our study showed statistically significant differences between infected patients without SIRS and sepsis patients: IL6 was markedly higher in sepsis patients than in patients without SIRS. Overall these results match those of other studies analyzing the levels of IL6 in infected patients without SIRS and sepsis in surgery patients, neonatal age patients, children with acute apendicitis [33-36]. The median levels of IL6 were significantly different among infected patients with SIRS and sepsis patients, and among severe sepsis and sepsis patients, these results correlate Gaini et al. studies [10,12,31]. Median IL6 level for severe sepsis patients in our study was 290 $\mathrm{pg} / \mathrm{ml}$, which correlate with the median IL6 levels from Gaini et al. [31], where medium IL6 levels were 199.3 $\mathrm{pg} / \mathrm{ml}$ for severe sepsis. We found significant difference in IL6 levels among bacteraemic and non bacteraemic patients. IL6 levels $21.2 \mathrm{pg} / \mathrm{ml}$ and $178.1 \mathrm{pg} / \mathrm{ml}$ accordingly were detected, Gaini et al. [12] observed accordingly $50.3 \mathrm{pg} / \mathrm{ml}$ and $178.1 \mathrm{pg} / \mathrm{ml}$ in the same patients' groups. We detected a moderate correlation between IL 6 and LBP which is partly consistent with findings from other studies, where in one study a weak correlation was detected and in another a moderate connection was fixed [12,31]. In diagnosing bacteraemia we obtained a cut-off level of $58.7 \mathrm{pg} / \mathrm{ml}$ for IL-6 with a sensitivity of $80 \%$ and a specificity of $55.4 \%$. Our result is in contrast to results by Pavcnik-Arnol [16] who reported a cut-off of $43.2 \mathrm{pg} / \mathrm{ml}$ for bacterial neonatal sepsis diagnosis and Silveira et al. [36] who found an optimal cut-off of 32 $\mathrm{pg} / \mathrm{ml}$ for neonatal sepsis diagnosis on one side, and a cut-off value of $94.6 \mathrm{pg} / \mathrm{ml}$ from Gaini et al. [12] in diagnosing bacteraemia in adult population from another side. In our study on ROC analysis IL-6 performed good, with AUC 0.87, which is quite close to results of Groselj-Grenc [33] - AUC 0.776 for acute appendicitis diagnosis in children, and marginally different from results in Pavcnik-Arnol [16] study - AUC 0.67 for prediction of bacterial sepsis in neonates.

The statistically significant differences in median CRP levels observed between the three groups of children with different severity of infection were in line with the findings of other studies showing higher CRP levels with higher severity of infection in children [31,37].

Naturally, our study had some limitations. The number of patients was rather small due to refusal of study participants (29 patients refused to participate) and the lack of a control group. Furthermore, we included patients with strong suspected (but not confirmed) bacteraemia into the group with bacteraemia which may have caused misclassification bias. However, in clinical work this group would be considered as having bacteraemia and would receive adequate treatment reflecting the real situation in clinical practice. 
The issues to be improved are the number of patients included in the study, necessity of a control group consisting of healthy children, and the inclusion of children in the newborn age group. We have recognized the potential problems which we have to meet in future: difficulties to establish the control group - to receive the agreement from parents to take intravenous blood samples from healthy children will be complicated; difficulties to include newborn children in study due to local health-care system (newborn treatment is mainly organized in specialized centers at maternity departments). We have focused on research results that may be useful in future clinical practice for early severe infections diagnosis in children by using effective diagnostic markers.

\section{Conclusions}

The severity of an infection and bacteraemia seem to be associated with increased inflammatory markers levels in children with SIRS. Elevated levels of LBP, IL-6 and CRP were associated with a more severe level of infection in children. Whereas LBP, IL- 6 and CRP seem to be good markers to detect patients with bacteraemia, HMGB1 seem to be of minor importance and does not seem to have a diagnostic value in differentiating bacteraemic patients from those without bacteraemia. LBP, IL6 and CRP levels may serve as good biomarkers for identifying children with severe sepsis and bacteraemia and, thus, may be routinely used in clinical practice.

\section{Key messages}

- The role of HMGB1 as inflammatory cytokine in children has not been thoroughly explored. In our study levels of HMGB1 were not statistically higher in sepsis patients and HMGB1 did not enable to detect bacteraemia in children.

- LBP, IL-6 and CRP levels are associated with the severity of infection in children population.

- IL-6 and CRP are probably the best markers of bacteraemia in children.

\footnotetext{
Acknowledgements

The authors acknowledge the National Research Program in Medicine "Multidisciplinary research consortium on major pathologies threatening the life expectancy and quality of life of the Latvian population" and European Social Fund (ESF).

\section{Author details}

${ }^{1}$ Riga Stradins University, Chair of Pediatrics, Riga, Latvia. ${ }^{2}$ Riga Stradins University, Chair of Physics, Riga, Latvia.
}

\section{Authors' contributions}

JP planned the study, wrote the protocol, collected and analyzed data, wrote the report. IG was responsible for study planning, collection and analyzing the data, she was involved in practical clinical aspects. IK was responsible for data analysis, he was involved in manuscript revision, DG was involved in study planning, in revising of manuscript. All authors read and approved the manuscript.

\section{Competing interests}

The authors declare that they have no competing interests.

Received: 20 April 2009

Accepted: 16 February 2010 Published: 16 February 2010

\section{References}

1. Proulx F, Fayon M, Farrell CA, Lacroix J, Gauthier M: Epidemiology of sepsis and multiple organ dysfunction syndrome in children. Chest 1996, 109:1033-1037.

2. Watson RS, Carcillo JA: Scope and epidemiology of pediatric sepsis. Pediatric Crit Care 2005, 6(Suppl 3):3-4.

3. Watson RS, Carcillo JA, Linde-Zwirble WT, Clermont G, Lidicker J, Angus D: The epidemiology of severe sepsis in children in the United States. Am J Respir Crit Care Med 2003, 167:695-701.

4. Gardovska D, Laizâne G, Grope I: Sepsis outcomes and early diagnostic peculiarities in tertiary level Children's hospital in Latvia. Riga Stradins University Scientific Proceedings 2001, 77-83.

5. Randolph AG: The purpose of the 1st International Sepsis Forum on Sepsis in Infants and Children. Pediatr Crit Care Med 2005, 6(Suppl 3): S1-S2.

6. Brilli RJ, Goldstein B: Pediatric sepsis definitions: past, present, future. Pediatr Crit Care Med 2005, 6(Suppl 3):6-8.

7. Mishra K, Jacobs SE, Doyle LW, Garland SM: Newer approaches to the diagnosis of early onset neonatal sepsis. Arch Dis Child Fetal Neonatal Ed 2006, 91(3):F208-212

8. Sunden-Cullberg J, Norrby-Teglund A, Teutiger CJ: The role of high mobility group box-1 protein in severe sepsis. Curr Opin in Infec Dis 2006, 19:231-236.

9. Wang $\mathrm{H}$, Bloom $\mathrm{O}$, Zhang $\mathrm{M}$, Vishnubhakat JM, Ombrellio $\mathrm{M}$, Che J, Frasier A, Yang H, Ivanova S, Borovikova L: HMGB-1 as a late mediator of endotoxin lethality in mice. Science 1999, 285:248-251.

10. Gaini S, Pedersen SS, Koldkjar OG, Pedersen C, Moller HJ: High mobility group box-1 protein in patients with suspected community - acquired infections and sepsis: a prospective study. Crit Care 2007, 11:R32.

11. Hatada T, Wada H, Nobori T, Okabayashi K, Maruyama K, Abe Y, Uemoto S, Yamada S, Maruyama I: Plasma concentrations and importance of High Mobility Group Box1 protein in the prognosis of organ failure in patients with disseminated intravascular coagulation. Tromb Haemost 2005, 94:975-979.

12. Gaini S, Koldkjar OG, Moller HJ, Pedersen C, Pedersen SS: A comparision of high- mobility group box-1 protein, lipopolysaccharide - binding protein and procalcitonin in severe community - acquired infections and bacteraemia: a prospective study. Crit Care 2007, 11:R76.

13. Meisner M: Biomarkers of sepsis: clinical useful?. Curr Opin Crit Care 2005, 11:473-480.

14. Berner R, Furll B, Stelter F, Drose J, Muller HP, Schutt C: Elevated levels of lipopolysaccharide-binding protein and soluble CD14 in plasma in neonatal early-onset sepsis. Clin Diagn Lab Immunol 2002, 9:440-445.

15. Ubenauf KM, Krueger M, Henneke P, Berner R: Lipopolysaccharide binding protein is a potential marker for invasive bacterial infections in children. The Ped Infec Dis J 2007, 26:159-162.

16. Pavcnik-Arnol M, Hojker S, Derganc M: Lipopolysaccharide - binding protein in critically ill neonates and children with suspected infection: Comparision with procalcitonin, interleukin-6, and C - reactive protein. Intensive Care Med 2004, 30:1454-1460.

17. Ng PC, Li K, Wong RP: Proinflammatory and anti - inflammatory cytokine responses in preterm infants with systemic infections. Arch Dis Child Fetal Neonatal Ed 2003, 88:F209-213.

18. Carcillo JA, Planquois JS, Goldstein B: Early markers of infection and sepsis in newborns and children. Advances in Sepsis 2006, 4:118-125.

19. Dahmet MK, Randolph A, Viatli S, Quasney MQ: Genetic polymorphisms in sepsis. Pediatric Crit Care Med 2005, 6(Suppl 3):61-73.

20. Ng PC, Lam SH: Diagnostic markers for neonatal sepsis. Curr Opin Pediatr 2006, 18:125-131.

21. Goldstein B, Giroir B, Randolph A, the members of the International Consensus Conference on Pediatric Sepsis: International Pediatric Sepsis 
Consensus Conference: Definitions for sepsis and organ dysfunction in pediatrics. Pediatr Crit Care Med 2005, 6(Suppl 3):2-8.

22. See LL: Bloodstream infection in children. Pediatr Crit Care Med 2005, 6(3 Suppl):S42-4.

23. Yang $H$, Ochani $M$, Li J, Tanovic M, Harris HE, Susarla S, Ulloa L, Wang H, DiRaimo R, Czura CJ, Wang H, Roth J, Warren HS, Fink MP, Fenton MJ, Andersson U, Tracey KJ: Reversing established sepsis with antagonists of endogenous HMGB1. Proc Natl Acad Sci USA 2004, 101:296-301.

24. Wang H, Vishnubhakat JM, Bloom O, Zhang M, Ombrellino M, Sama A, Tracey KJ: Proinflammatory cytokines (tumor necrosis factor and interleukin1) stimulates release of high mobility group protein 1 by pituicytes. Surgery 1999, 126:389-392.

25. Sunden-Cullberg J, Norrby-Teglund A, Rouhianen A, Rauvala H, Herman G, Tracey K, Lee ML, Andersson J, Tokics L, Treutiger CJ: Persistent elevation of high mobility group box -1 protein (HMGB1) in patients with severe sepsis and septic sock. Crit Care Med 2005, 33:564-573.

26. Angus DC, Yang L, Kong L, Kellum JA, Delude RL, Tracey K, Weissfeld L, GenIMS Investigators: Circulating high-mobility group box 1 (HMGB1) concentrations are elevated in both uncomplicated pneumonia and pneumonia with severe sepsis. Crit Care Med 2007, 35:1061-1067.

27. Fink MP: Bench- to-bedside review: High - mobility box 1 and critical illness. Critical Care 2007, 11:229.

28. Yasuda T, Ueda T, Takeyama Y, Shinzeki M, Sawa H, Nakajima T, Ajiki T, Fujino $Y$, Suzuki $Y$, Kuroda Y: Significant increase of serum high-mobility group box chromosomal protein 1 levels in patients with severe acute pancreatitis. Pancreas 2006, 33:359-363.

29. Blairon L, Wittebole X, Laterre PF: Lipopolysaccharide-binding protein serum levels in patients with severe sepsis due to gram-positive and fungal infections. J Infect Dis 2003, 187:287-291.

30. Froon AH, Bemelmans MH, Greve JW, Linden van der CJ, Buurman WA: Increased plasma concentrations of soluble tumor necrosis factor receptors in sepsis syndrome: Correlation with plasma creatinine values. Crit Care Med 1994, 22:803-809.

31. Gaini S, Koldkjar, Pedersen C, Pedersen SS: Procalcitonin, lipopolysaccharide-binding protein, interleukin-6 and C-reactive protein in community-acquired infections and sepsis: a prospective study. Crit Care 2006, 10:R53.

32. Pavcnik-Arnol M, Hojker S, Derganc M: Lipopolysaccharide-binding protein, lipopolysaccharide, and soluable CD14 in sepsis of critical ill neonates and children. Inten Care Med 2007, 33:1025-1032.

33. Kocabas E, Sarikcioglu A, Aksaray N, Seydaoglu G, Seyhun Y, Yaman A: Interleukin-6 and lipopolysaccharide-binding protein in acute appendicitis in children. Scand J Clin Lab Invest 2007, 67:197-206.

34. Mokart D, Merlin M, Sannini A: Procalcitonin, interleukin 6 and systemic inflammatory response syndrome (SIRS): early markers of postoperative sepsis after major surgery. BJA 2005, 94:767-773.

35. Miyaoka K, Iwase M, Suzuki $R$, Kondo G, Watanabe $H$, Ito D, Naqumo M: Clinical evaluation of circulating interleukin- 6 and interleukin-10 levels after surgery induced inflammation. J Surg Res 2005, 125:144-150.

36. Silveira RC, Procionoy RS: Evaluation of interleukin-6, tumor necrosis factor-alpha and interleukin- 1 beta for early diagnosis of neonatal sepsis. Acta Paediatr 1999, 88:647-650

37. Kocabas E, Sarikcioglu A, Aksaray N, Seydaaaaoglu : Role of procalcitonin, C reactive protein, interleukin-6, interleukin-8 and tumor necrosis factor alfa in the diagnosis of neonatal sepsis. The Turkish Journal of Pediatrics 2007, 49:7-20

\section{Pre-publication history}

The pre-publication history for this paper can be accessed here:http://www. biomedcentral.com/1471-2334/10/28/prepub

doi:10.1186/1471-2334-10-28

Cite this article as: Pavare et al: High-mobility group box-1 protein, lipopolysaccharide-binding protein, interleukin- 6 and C-reactive protein in children with community acquired infections and bacteraemia: a prospective study. BMC Infectious Diseases 2010 10:28.

\section{Submit your next manuscript to BioMed Central and take full advantage of:}

- Convenient online submission

- Thorough peer review

- No space constraints or color figure charges

- Immediate publication on acceptance

- Inclusion in PubMed, CAS, Scopus and Google Scholar

- Research which is freely available for redistribution

Submit your manuscript at www.biomedcentral.com/submit 